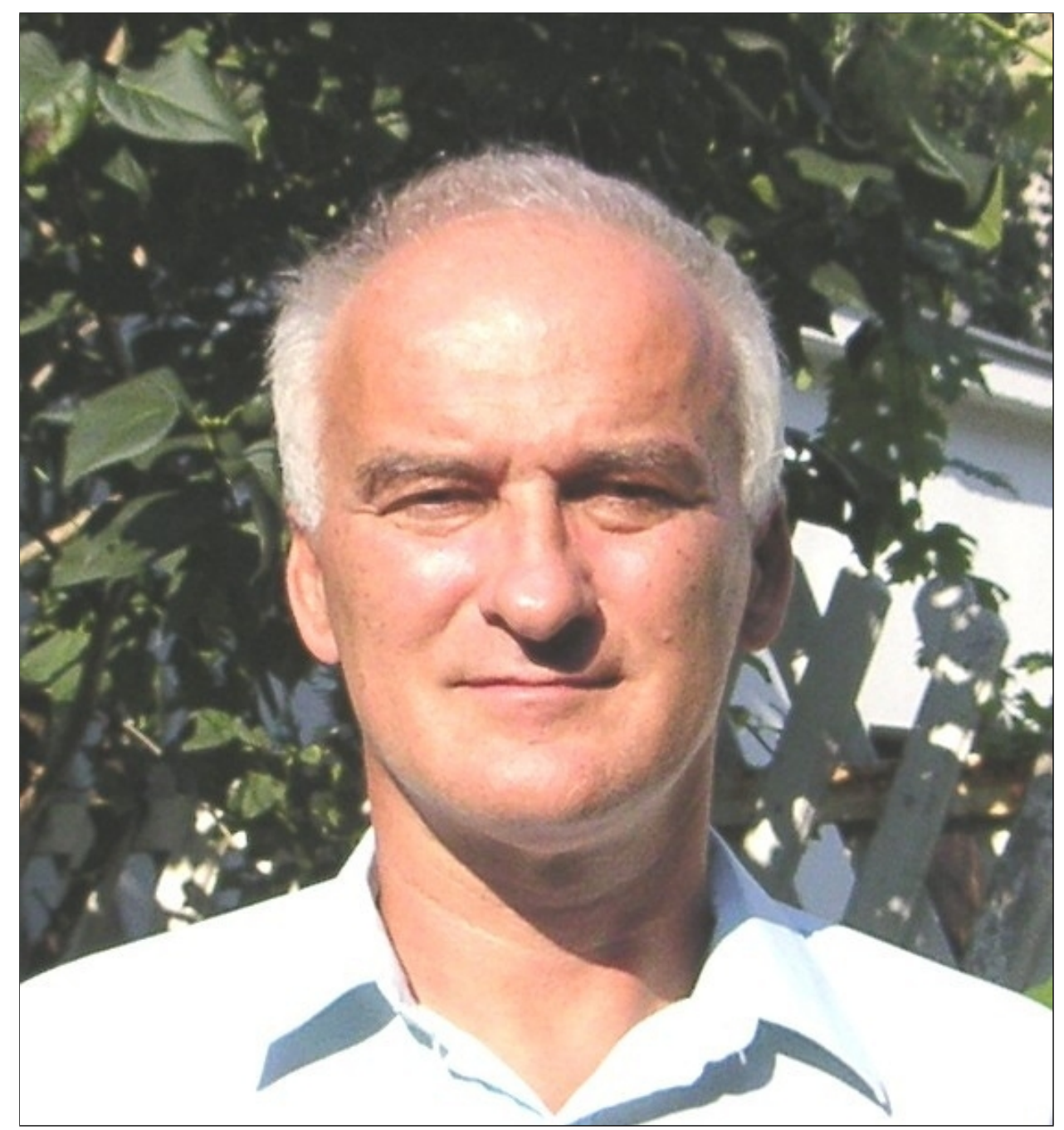

Professor ZoLTÁN ÉsIK (1951-2016) 



\section{In Memoriam Zoltán Ésik}

We got the news via e-mail that our colleague Zoltán Ésik, professor at the University of Szeged, passed away in a hotel in Reykjavik on 25th May 2016. He had plans for future research, teaching, and advising students, therefore the news was so unexpected and inconceivable that at first we did not believe it, and we did not dare to say it out loud. Just few days before we had talked to him, and few hours before we had exchanged emails about work and plans to be accomplished. But the news sadly proved to be true.

Zoltán's special talent for mathematics emerged as early as his school years. As a student of the specialised mathematics programme of the High School of the University of Szeged he achieved notable results at the competition of the Mathematical Journal for High Schools. This competition is more than 120 years old in Hungary and it serves as a platform for high school students to show their skills and talents. Several famous Hungarian mathematicians took their first steps in this competition toward research. It came naturally for Zoltán to continue his studies in mathematics at the University of Szeged, where he earned his degree in 1974. After graduation he got a position at the university and he remained a distinguished and highly respected member of our institute. As a young faculty member, he had long hair, wore blue jeans, and it looked like he was still a student. He was happy to stop for a chat with students. Many of them realized only that he was a teacher when he appeared in front of them in the class room and started his lectures. Even at such a young age, he introduced students to many subjects that became fundamental later on. Those who knew him well, praised his talent, his hard work and zest for science.

His professional career followed an unbroken path. He earned the title doctor of university in 1979, and became the candidate of science (CSc, an academic degree that used to be awarded in former Eastern Bloc countries, in Hungary by the Hungarian Academy of Sciences) in 1985. Then he earned the title of doctor of science (DSc) in 1996, which is also awarded by the Academy and is still the most prestigious academic rank in Hungary today. He was appointed as full professor in 1997, and in 2003 he became the head of the Department of Foundations of Computer Science of the University of Szeged.

Only some highlights of his work can be mentioned within the scope of this article. I only list a few of his numerous results and might even miss the most significant ones. I know that he would not mind the short summary of his achievements, since he never liked praise.

As a university teacher he made special efforts to introduce modern subjects taught at western universities into the curriculum, to bring the newest results and research topics to the University of Szeged. This was crucial in the era of the 
iron curtain and before the internet age. He travelled a lot to learn about new ideas, to broaden his own knowledge, which he later transferred to his students. He liked visiting foreign institutes, and it is a cruel twist of fate, that he had died during such a trip. In Szeged he was the first to teach category theory, theory of computability and complexity, logic in computer science, connections of automata and logics, fixed point theory and its applications to students of computer science. He devised the educational profile and the subjects taught at the Department of Foundations of Computer Science. He wrote four university textbooks, supervised winning papers at Conferences of Association of Students in Science (a Hungarian specialty), and successfully defended doctoral theses. He was instrumental to start the professional career of several colleagues, the author of this article being one of them. I wrote my university thesis under his supervision in 1979, although he was only four years older than me. A number of his former students are now leading experts or teachers at universities, not only in Hungary but also abroad.

He obtained his first results in the field of structural properties of finite automata, and later in the theory of tree automata and tree transducers. He was the first to prove the often cited result, in his thesis for doctor of university, that the equivalence problem of deterministic tree transducers is decidable. In the mid 1980 's, probably due to the influence of Stephen Bloom, he turned his attention towards iteration theories. His field of research later became even more complex, and extended towards algebraic methods in computer science, category theory, theory of fixed points, modern logic in computer science, order theory, and semiring theory. He achieved thoughtful and essential results in all these fields. In the second half of his career he worked together and obtained important results with Werner Kuich in the theory of semirings and weighted automata. He had a special talent to recognize that in the seemingly different fields of computer science the same principles are in effect and used. One of his most important observations was that most fixed point models commonly used in computer science share the same equational properties.

His unparalleled talent, diligence, and his love for work resulted in countless publications. He worked together with more than 40 co-authors. The number of his scientific articles is above 230 , and he edited nearly 30 collections of scientific papers. He is the author of the monographs Iteration Theories (with Stephen Bloom) and Modern Automata Theory (with Werner Kuich) which are regarded as fundamental handbooks all over the world. The latter was also translated into Russian. He gave talks at more than 50 universities, and was invited speaker at more than 30 conferences and workshops. His most significant conference activity was probably his talk at the conference of Mathematical Foundations of Computer Science in Milan in 2015. This was the 40th MFCS Conference, and Zoltán was the 'anniversary invited speaker' of the event. These numbers already alone are very impressive, but they are even more compelling when we recall the precision, the high standard, and the elegance that characterised each of his articles and talks. 
Organising and participating in conferences were particularly important for him. He was a member of the steering committee of the conferences FCT, CAI, AFL, and FICS, and of the program committee of nearly 60 international conferences. It was specifically due to his scientific reputation and prestige that many renowned international conferences, like FCT, CSL, and MFCS could be organised in Hungary, most of them in Szeged. He played an essential role in moving the quality of the traditional Hungarian conference series Automata and Formal Languages gradually closer to European standards.

He was a member of the editorial board of a number of prestigious computer science journals, being the only Hungarian member of the editorial board of Theoretical Computer Science, a leading journal in the field. For three terms he was a member of the Council of the European Association for Theoretical Computer Science and for one term of the European Association for Computer Science Logic. He represented the Hungarian computer science community in Section TC1 of the International Federation for Information Processing. As an acknowledgement of his work, he was an elected member of The Academy of Europe in 2010 and earned the title Fellow of the EATCS in 2016, given only for the greatest scientists.

He received numerous Hungarian awards as well, such as the Kató Rényi Research Award and the Gyula Farkas Research Award of the János Bolyai Mathematical Society for outstanding mathematicians, the Award for Excellence, and in 2005 the title of Master Teacher. He also earned Humboldt and Fulbright research scholarships, and the Széchenyi Professorial Award in Hungary.

Zoltán Ésik was, without doubt, one of the most prominent figures in theoretical computer science. His results contributed significantly to the development of the foundations of this discipline. His achievements and efforts were crucial to the establishment of the Institute of Informatics of the University of Szeged an internationally acknowledged research institute, and putting it on the map of science. His death is a serious loss to the Institute, to the University of Szeged, and to the community of theoretical computer science.

Dear Professor Ésik, dear Zoli, your memory will stay with us forever. Farewell to you and may you rest in peace!

\section{Zoltán Fülöp}

Szeged, December 2016 